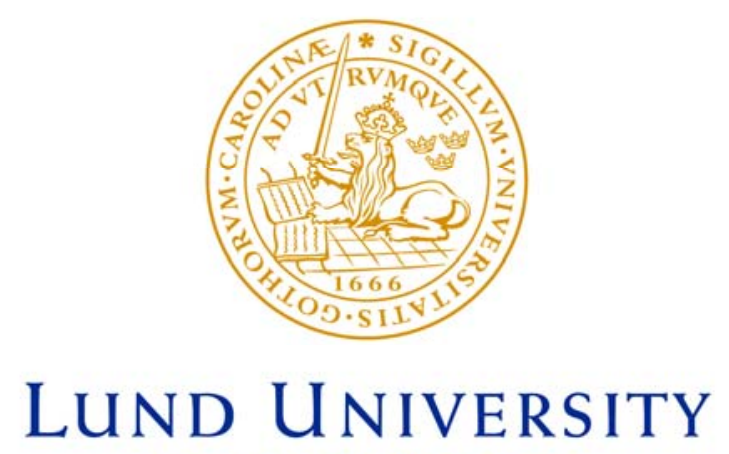

Faculty of Medicine

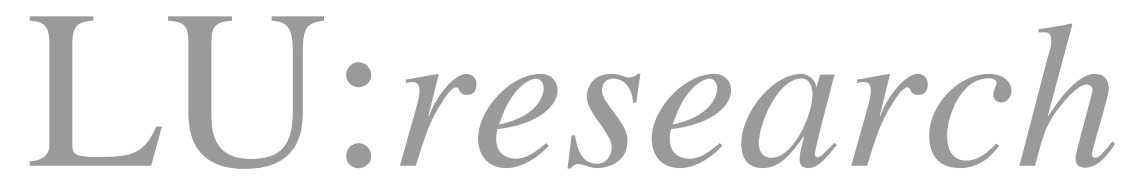

Institutional Repository of Lund University

This is an author produced version of a paper published in Rapid communications in mass spectrometry : RCM. This paper has been peer-reviewed but does not include the final publisher proof-corrections or journal pagination.

Citation for the published paper:

Lindh, Christian $\mathrm{H}$ and Littorin, Margareta and Amilon, Asa and Jonsson, Bo A G.

"Analysis of 3,5-dichloroaniline as a biomarker of vinclozolin and iprodione in human urine using liquid chromatography/triple quadrupole mass spectrometry". Rapid communications in mass spectrometry : RCM, 2007, Vol: 21, Issue: 4, pp. 536-42.

\title{
http://dx.doi.org/10.1002/rcm.2866
}

Access to the published version may require journal subscription.

Published with permission from: John Wiley And Sons Ltd 


\section{Analysis of 3,5-dichloroaniline as a biomarker of vinclozolin and iprodione in human urine using liquid chromatography triple quadrupole mass spectrometry.}

Christian H. Lindh ${ }^{1}$, Margareta Littorin ${ }^{1}$, Åsa Amilon ${ }^{1}$, and Bo A. G. Jönsson ${ }^{1}$

${ }^{1}$ Department of Occupational and Environmental Medicine, Institute of Laboratory Medicine, University Hospital, SE-221 85 Lund, Sweden

running title : dichloroaniline as a biomarker of vinclozolin and iprodione

* Corresponding author: Christian Lindh, Department of Occupational and Environmental Medicine, University Hospital, SE-221 85 Lund, Sweden. Tel: (+46) 46 173819; fax: (+46) 46-143702; e-mail: Christian.lindh@med.lu.se 
The fungicides vinclozolin and iprodione are widely used in agriculture. These pesticides are dicarboximide fungicides containing the common moiety 3,5-dichloroaniline (3,5-DCA). It has been suggested that low-level exposures to such compounds may be associated with adverse health effects such as endocrine disruption.

In this study a method using liquid chromatography triple quadrupole mass spectrometry (LCMS/MS) was developed for the analysis of 3,5-DCA as a biomarker of exposure to these fungicides in human urine. The urine samples were treated by basic hydrolysis to degrade the fungicides, their metabolites and conjugates to 3,5-DCA. The 3,5-DCA was then extracted using toluene and derivatized using pentafluoropropionic anhydride (PFPA). Analysis of the derivative was carried out using selected reaction monitoring (SRM) in the negative ion mode. Quantification of the derivative was performed using $\left[{ }^{13} \mathrm{C}_{6}\right]$ labeled 3,4-DCA as an internal standard with good precision and linearity in the range $0.1-200 \mathrm{ng} / \mathrm{mL}$ urine. The limit of detection was determined to $0.1 \mathrm{ng} / \mathrm{mL}$. The metabolites in urine were found stable at storage in $-20^{\circ} \mathrm{C}$. To validate $3,5-\mathrm{DCA}$ as a biomarker the method was applied in a human experimental exposure to iprodione and vinclozolin. Two healthy volunteers received $200 \mu \mathrm{g}$ single oral doses of each pesticide followed by urine sampling during 72-120h post exposure. Between $78-107 \%$ of the dose was recovered as 3,5-DCA in the urine after exposure. 
The dicarboximide fungicides vinclozolin, iprodione and procymidone are commonly used for the control of diseases on fruits, vegetables, ornamental plants and turf grasses. Human exposure to these fungicides can occur from occupational use but the general public may also be exposed via ingestion of contaminated produce.

Vinclozolin has been classified as an endocrine disrupting chemical and it has been suggested that low-level exposures may be associated with adverse health effects. Vinclozolin is an androgen receptor antagonist with effects shown in adult, pubertal and neonatal rodents. ${ }^{1-4}$ In addition, epigenetic transgenerational effects have been observed in rats. ${ }^{5}$ The US EPA suggests that vinclozolin-induced malformations of the male reproductive tract are highly plausible to occur in humans. ${ }^{6}$ However, only one report on human effects has been published and in that no antiandrogenic or reproductive effects were found after occupational exposure to vinclozolin. ${ }^{7}$ Iprodione is chemically similar in structure to vinclozolin but there are few reports on its toxicity. In a study on rats by Gray et al., ${ }^{8}$ no maternal or fetal endocrine toxicity was observed. The two fungicides contain the common moiety 3,5-dichloroaniline (3,5-DCA), which also has been found as a metabolite after exposure, this isomer has been shown to be nephrotoxic. ${ }^{9}$

A prerequisite for epidemiological studies, and for determination of exposure-response relationships, is an accurate measurement of exposure. There is a lack of human exposure and effect data for fungicides overall, including iprodione and vinclozolin. Therefore, reliable analytical methods are required. Several analytical methods have been presented on measurement of metabolites in biological samples.

The use of 3,5-DCA as a biomarker has been suggested for several of the dicarboximide fungicides such as vinclozolin, iprodione and procymidone. Several LC methods with UV or EC detection have been reported for determination of DCA in human urine ${ }^{10,11}$ or in biological samples from mouse, rat and rabbit. ${ }^{12,13}$ Although these methods may be applicable for high 
occupational exposures, they are insufficient for assessment of low-level exposures in the general population. More sensitive methods for determination of DCA have also been presented, then utilising gas chromatography with MS detection. ${ }^{14-19}$ Several of these methods are rather laborious but with sufficient detection limits. Also, the use of the more robust LCMS/MS techniques for determination of aromatic amines after derivatization using PFPA in biological samples has been described. ${ }^{20}$ However, no data has been published on DCA analysis using LC-MS/MS.

Knowledge of human pesticide metabolism and basic elimination kinetics are needed for the interpretation of biomarker data. Usually assumptions about absorbed dose and metabolite excretion are made from animal data. ${ }^{21,22}$ Therefore, there is a need for controlled human experimental exposures to validate biomarkers of exposure. In recent years very few studies have been conducted, mainly hindered by ethical issues. However, with the rapid development of advanced LC-MS/MS techniques, low level environmental exposures to pesticides may be monitored. Therefore, the analytical techniques are sensitive enough to conduct human experimental exposures to pesticides with exposure doses below the recommended acceptable daily intake (ADI).

The aim of this study was to develop a LC-MS/MS method for the analysis of 3,5-DCA in human urine. The biomarker 3,5-DCA was also validated in a human experimental exposure study after oral ingestion of vinclozolin and iprodione.

\section{EXPERIMENTAL}

\section{Chemicals and Materials}

$\left[{ }^{13} \mathrm{C}_{6}\right]-3,4-\mathrm{DCA}$ was purchased from Cambride Isotope Laboratories (Andover, MA, USA). Ethanol was from Kemetyl (Haninge, Sweden). Acetonitrile, methanol and toluene came from 
Lab-Scan (Dublin, Ireland). Acetic acid, disodium hydrogen phosphate dihydrate $\left(\mathrm{Na}_{2} \mathrm{HPO}_{4} \cdot 2 \mathrm{H}_{2} \mathrm{O}\right)$, sodium dihydrogen phosphate monohydrate $\left(\mathrm{NaH}_{2} \mathrm{PO}_{4} \cdot \mathrm{H}_{2} \mathrm{O}\right)$, and sodium hydroxide $(\mathrm{NaOH})$ were obtained from Merck (Darmstadt, Germany). 3,5-DCA, iprodione, pentafluoropropionic anhydride (PFPA) and, vinclozolin were from Sigma-Aldrich (St. Louis, MO, USA). Water was produced by an USF Elga Maxima system (USF Elga., High Wycombe, UK).

Urine samples were collected in polyethylene bottles. Polyethylene plastic test tubes $(13 \mathrm{~mL})$ with screw caps (Sarstedt, Numbrecht, Germany) were used for storage of urine samples and in sample preparation.

\section{Instrumentation}

The analysis of the samples was performed using a triple quadrupole mass spectrometer with electrospray ionization (ESI) on a turbo ionspray source (API 3000, Applied Biosystems, Foster City, CA, USA) coupled to a liquid chromatography system from Perkin Elmer (Norwalk, CT, USA; LC-MS/MS). The MS analyses were performed using selected reaction monitoring (SRM) in the negative ion mode. To establish the appropriate SRM conditions, standard solutions were infused into the MS for optimization. Collision-induced dissociation (CID) of each $[\mathrm{M}-\mathrm{H}]^{-}$was performed. The $\mathrm{SRM}$ transition $\mathrm{m} / \mathrm{z} 306.1 \rightarrow 185.8$ was chosen as the quantifier ion at a collision energy of $-29 \mathrm{~V}$. The transition $\mathrm{m} / \mathrm{z} 306.1 \rightarrow 119.0$ was used as a qualifier ion, while the internal standard was monitored at $\mathrm{m} / \mathrm{z} 312.1 \rightarrow 119.0$, both using a collision energy at $-25 \mathrm{~V}$. The declustering potential was set at $-30 \mathrm{~V}$ and the focusing potential at $-130 \mathrm{~V}$. The temperature of the auxiliary gas was set to $350^{\circ} \mathrm{C}$ and the ion spray voltage was $-4200 \mathrm{~V}$. Nitrogen was used as the curtain, turbo ionspray, collision and, nebulizer gas. All data acquisition and processing were performed using Analyst 1.4.1 software (Applied Biosystems). 
Mettler AE163 and PE 600 (Stockholm, Sweden) balances were used to accurately weigh the chemicals. A URC-PN hand refractometer from Atago (Tokyo, Japan) was used for determination of urine density. An IKA Vibrax VXR shaker table (Janke \& Kunkel, Staufen, Germany) was used for liquid-liquid extractions. A Sigma 3E-1 centrifuge (Osterode am Harz, Germany) was used for liquid phase separation. A drying oven (Termaks 85-TS8136, Bergen, Norway) was used for hydrolysis of the biological samples and a SPD2010 SpeedVac $^{\circledR}$ (ThermoSavant, Waltham, MA, USA) for sample evaporation.

\section{Preparation of standards}

Stock solutions were prepared by dissolving accurately weighed amounts of 3,5-DCA and $\left[{ }^{13} \mathrm{C}_{6}\right]-3,4-\mathrm{DCA}$ in $10 \mathrm{~mL}$ acetonitrile. Stock solutions were prepared in duplicates. Standard solutions were further prepared by diluting the stock solutions in acetonitrile. Calibration standards were prepared by spiking urine with the standard solutions. The levels of 3,5-DCA in the spiked calibration standards were in the range $0.1 \mathrm{ng} / \mathrm{mL}$ to $200 \mathrm{ng} / \mathrm{mL}$. Urine for the calibration standard curves was obtained from healthy volunteers at our laboratory.

\section{Sample preparation}

One $\mathrm{mL}$ of urine and $10 \mathrm{ng}$ of the internal standard $\left[{ }^{13} \mathrm{C}_{6}\right]-3,4-\mathrm{DCA}$ in $100 \mu \mathrm{L}$ acetonitrile was added to $13 \mathrm{~mL}$ polyethylene plastic test tubes. One $\mathrm{mL}$ of $10 \mathrm{M} \mathrm{NaOH}$ was added to the urine samples. They were then hydrolyzed for $2 \mathrm{~h}$ in $100^{\circ} \mathrm{C}$. After hydrolysis, the samples were extracted with $2 \mathrm{~mL}$ toluene by vigorous shaking for $15 \mathrm{~min}$. The samples were centrifuged and frozen at $-20^{\circ} \mathrm{C}$, to facilitate phase separation. The liquid toluene phase was transferred to a new test tube and derivatized by addition of $30 \mu \mathrm{L}$ of PFPA. The samples were shaken for $5 \mathrm{~min}$ and the excess reagent was removed by extraction with $1 \mathrm{~mL}$ of $0.1 \mathrm{M}$ 
phosphate buffer, $\mathrm{pH}$ 7.5. The samples were again frozen at $-20^{\circ} \mathrm{C}$ for phase separation and the organic phase was transferred to a new test tube and evaporated in a SpeedVac ${ }^{\circledR}$. The dry residues were dissolved in $100 \mu \mathrm{L}$ acetonitrile and transferred to $200 \mu \mathrm{L}$ insert vials. The samples were kept frozen at $-20^{\circ} \mathrm{C}$ until analyzed using LC-MS/MS .

\section{Analysis}

Immediately prior to analysis the analytical vials were centrifuged for precipitation of particles. Four $\mu \mathrm{L}$ was injected on a Rapid Resolution Zorbax Eclipse $\mathrm{XDB}_{18}$ column (2.1 mm x 50 mm, $1.8 \mu \mathrm{m}$ particles; Agilent, Palo Alto, CA, USA). The mobile phase consisted of water and methanol, both containing $0.5 \%$ acetic acid. The separation was carried out using a linear gradient starting from $60 \%$ to $98 \%$ methanol in $6 \mathrm{~min}$, followed by $1 \mathrm{~min}$ isocratic flow at $98 \%$ methanol. The flow rate was $0.2 \mathrm{~mL} / \mathrm{min}$. The gradient was optimized for peak separation of the DCA isomers: 2,6-DCA, 3,4-DCA and 3,5 DCA. Concentrations were determined by peak area ratios of 3,5-DCA and $\left[{ }^{13} \mathrm{C}_{6}\right]-3,4-\mathrm{DCA}$. All samples were prepared in duplicates and each of these samples was analyzed twice. The mean value was used in further calculations.

\section{Method validation}

The limit of detection (LOD) was determined as defined by Miller and Miller ${ }^{23}$ as the analyte concentration giving a signal equal to the blank signal plus three times the standard deviation of the blank signal. The mean concentrations of the peak at the same retention time as derivatized 3,5-DCA plus three times the standard deviation of the means were determined in 10 water blanks and then used to calculate the LOD. 
To evaluate the degradation of the fungicides, their metabolites and possible conjugated metabolites to the common moiety 3,5-DCA, urine samples were treated with basic hydrolysis. Urine samples $(1.0 \mathrm{~mL})$ from the experimentally exposed volunteers (see below) were treated by hydrolysis at $5 \mathrm{M} \mathrm{NaOH}$. The samples were heated at $100^{\circ} \mathrm{C}$ for $0.5,1,2,4 \mathrm{~h}$ and analyzed with the described method. Also, blank urine samples $(1.0 \mathrm{~mL})$ were spiked with $10 \mathrm{ng}$ of vinclozolin, iprodione or 3,5-DCA. The samples were then hydrolyzed at 1 or $5 \mathrm{M} \mathrm{NaOH}$. The samples were heated at $100^{\circ} \mathrm{C}$ for $2,4,6$, and $24 \mathrm{~h}$ and analyzed with the described method.

The repeatability of the method was determined by analyzing 10 urine samples spiked with $1.0 \mathrm{ng}$ and $10 \mathrm{ng}$ of 3,5-DCA respectively. The samples were analyzed in one analytical sample set and during one day. The reproducibility of the method was determined by comparing quantified concentrations in duplicate samples. The samples were prepared and analyzed in different analytical sample sets and on different days.

The stability of the urine samples after a long-term storage at $-20^{\circ} \mathrm{C}$ was determined by reanalyzing urine samples from the experimentally exposed volunteers (see below). The urine samples from the iprodione exposure were stored for 12 months after the first analysis. Five samples from the female volunteer and 5 from the male volunteer were selected for reanalysis. The urine samples from the vinclozolin exposure were stored for 7 months, 5 samples from the female volunteer and 5 from the male volunteer were reanalyzed.

\section{Subjects}

Two healthy volunteers, one female (age 61; weight $54 \mathrm{~kg}$ ) and one male (age 36; weight $75 \mathrm{~kg}$ ), participated in the study. They had given their written informed consent to participate in the study. The study was approved by the ethics committee at Lund University, Sweden (721-1395-05Mm). 


\section{Human experimental exposure}

Two experimental exposures were performed with iprodione and vinclozolin at two occasions with a three-month interval. An accurately weighed amount of iprodione (analytical grade) was dissolved in $10 \mathrm{~mL}$ of ethanol. An aliquot of the ethanol solution containing $200 \mu \mathrm{g}$ iprodione was added to $200 \mathrm{~mL}$ of orange juice. The two subjects received a single oral dose. All urine voided was collected. The first urine sample was collected immediately prior to the dosing and then in intervals ad libitum during $120 \mathrm{~h}$ post exposure. The dose of iprodione corresponds to $6 \%$ of the ADI for the female subject and $4 \%$ for the male subject. The ADI for iprodione suggested by the European Union (EU) is $0.06 \mathrm{mg} / \mathrm{kg} / \mathrm{day} .^{24}$

An accurately weighed amount of vinclozolin (analytical grade) was dissolved in $10 \mathrm{~mL}$ of ethanol. An aliquot of the ethanol solution containing $200 \mu \mathrm{g}$ vinclozolin was added to 200 $\mathrm{mL}$ of orange juice. The two subjects received a single oral dose. All urine voided was collected. The first urine sample was collected immediately prior to the dosing and then in intervals ad libitum during $72 \mathrm{~h}$ post exposure. The dose of vinclozolin corresponds to $37 \%$ of the ADI for the female volunteer while the male volunteer received 27\%. The ADI for vinclozolin suggested by the EU is $0.01 \mathrm{mg} / \mathrm{kg} / \mathrm{day}{ }^{24}$

In every urine sample, the volume, density and creatinine levels were determined. The creatinine levels were analyzed using an enzymatic method described by Mazzachi et al. ${ }^{25} \mathrm{~A}$ hand refractometer was used for determination of the urine density. The urine concentrations adjusted for density were calculated as $C_{d}=C(o b s) *(1.016-1) /(\rho-1)$. The $C_{d}$ is the corrected concentration, $\mathrm{C}(\mathrm{obs})$ is the observed concentration, $\rho$ is the specific density and 1.016 is the assumed average density as described by Boeinger et al. ${ }^{26}$ The urine samples were stored at $20^{\circ} \mathrm{C}$ until sample preparation and analysis. 
The half-life of elimination in urine was estimated from the slope of the curves in the log-linear concentration versus time plot. The urinary concentration was given at the mid point time between two sample collection times. The slope was calculated in two intervals between approximately $4 \mathrm{~h}-30 \mathrm{~h}$ and $28 \mathrm{~h}-72 \mathrm{~h}$ after the dose was given. The adjustments for urinary dilution using creatinine and density were compared.

\section{RESULTS AND DISCUSSION}

\section{Analysis}

Analysis of DCA without derivatization yielded a poor signal using ESI LC-MS/MS in both positive and negative ion mode. After derivatization using PFPA, a dramatic increase in sensitivity was observed in the negative ion mode. A product ion spectrum after CID of the molecular ion $[\mathrm{M}-\mathrm{H}]^{-}(\mathrm{m} / \mathrm{z}$ 306.1) is shown in Figure 1. Two abundant fragment ions were observed in the MS spectra of the derivatized 3,5-DCA and both were used for the SRM transitions. The fragment ions formed in the CID of the $[\mathrm{M}-\mathrm{H}]^{-}$ion likely corresponds to the loss of one $\mathrm{CF}_{3} \mathrm{CHF}_{2}$-group $[\mathrm{M}-\mathrm{H}]^{-} \rightarrow[\mathrm{M}-\mathrm{H}-120]^{-}$, and $[\mathrm{M}-\mathrm{H}]^{-} \rightarrow[119]^{-}$corresponding to the $\left[\mathrm{CF}_{3} \mathrm{CF}_{2}\right]^{-}$ion. The best signal to noise ratio was obtained for the transition $\mathrm{m} / \mathrm{z} 306.1 \rightarrow 185.8$ and was chosen as the quantifier ion. The transition $\mathrm{m} / \mathrm{z} 306.1 \rightarrow 119.0$ was used as a qualifier ion to confirm the identity of the derivatized 3,5-DCA.

A short $50 \mathrm{~mm}$ rapid resolution analytical column with $1.8 \mu \mathrm{m}$ particles and a diameter of 2.1 mm was used to separate the derivatized 3,5-DCA. Figure 2 shows that a clear separation between the isomers 2,6-DCA, 3,4-DCA and, 3,5-DCA could be achieved in a relatively short analytical run. The column is normally used for high pressure UPLC analysis. However, in this application a normal HPLC was used and operated at a pressure of about 200 bar with good results. Hundreds of injections could be performed on the analytical column without any 
signs of degradation. The analytical method is also applicable for analysis of 3,4-DCA but validation data will be presented elsewhere.

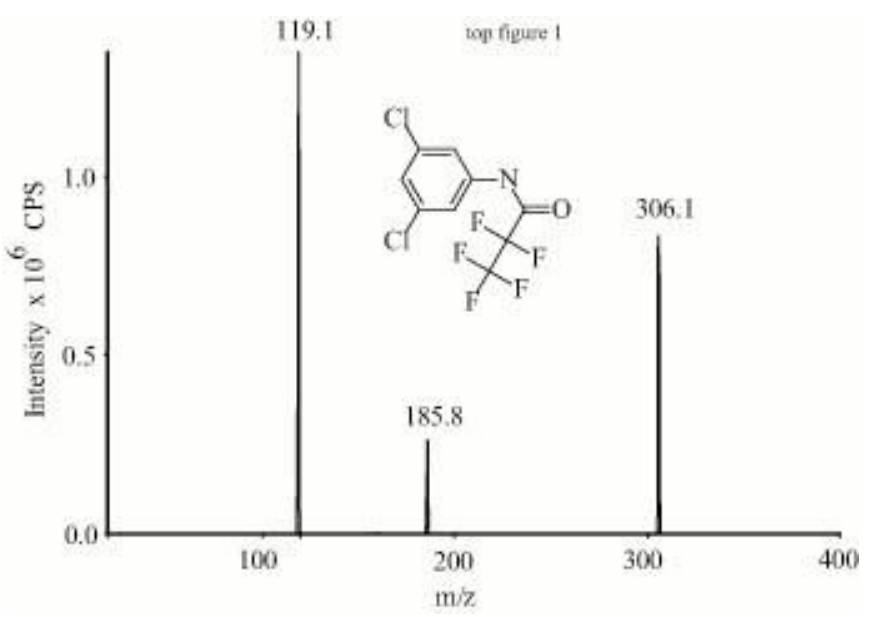

Figure 1. Product ion spectra of the ion $[\mathrm{M}-\mathrm{H}]^{-} \mathrm{m} / \mathrm{z} 306.1$ using collision-induced dissociation using LC-MS/MS.

\section{Method validation}

The LOD in this study was determined from the analysis of 10 water blanks. The LOD for the derivatized 3,5-DCA in the method was determined to $0.1 \mathrm{ng} / \mathrm{mL}$. To illustrate the background signal Figure 2(c) shows a chromatogram of a water blank used in the determination of the LOD. Figure 2(d) shows the chromatogram of a urine sample with a 3,5DCA level at the LOD. The LOD presented in this study is of the same magnitude as reported LODs using GC-MS. ${ }^{14-19}$

The calibration curves were linear in the range $0.1-200 \mathrm{ng} / \mathrm{mL}$ urine. The calibration curves with $r>0.99$ were obtained from the peak area ratios between the analyte peaks and the internal standard peaks from blank urine samples spiked with known concentrations of 3,5DCA. 
The reproducibility of the method was determined from duplicate analyses of samples from the experimental exposure. The coefficients of variation $(\mathrm{CV})$ were $11 \%$ at the mean concentration of $3 \mathrm{ng} / \mathrm{mL}$ ( $\mathrm{n}=66$, range $0.3-8 \mathrm{ng} / \mathrm{mL}$ ) and $6 \%$ at the mean concentration of 54 $\mathrm{ng} / \mathrm{mL}(\mathrm{n}=38$, range $9-180 \mathrm{ng} / \mathrm{mL})$.

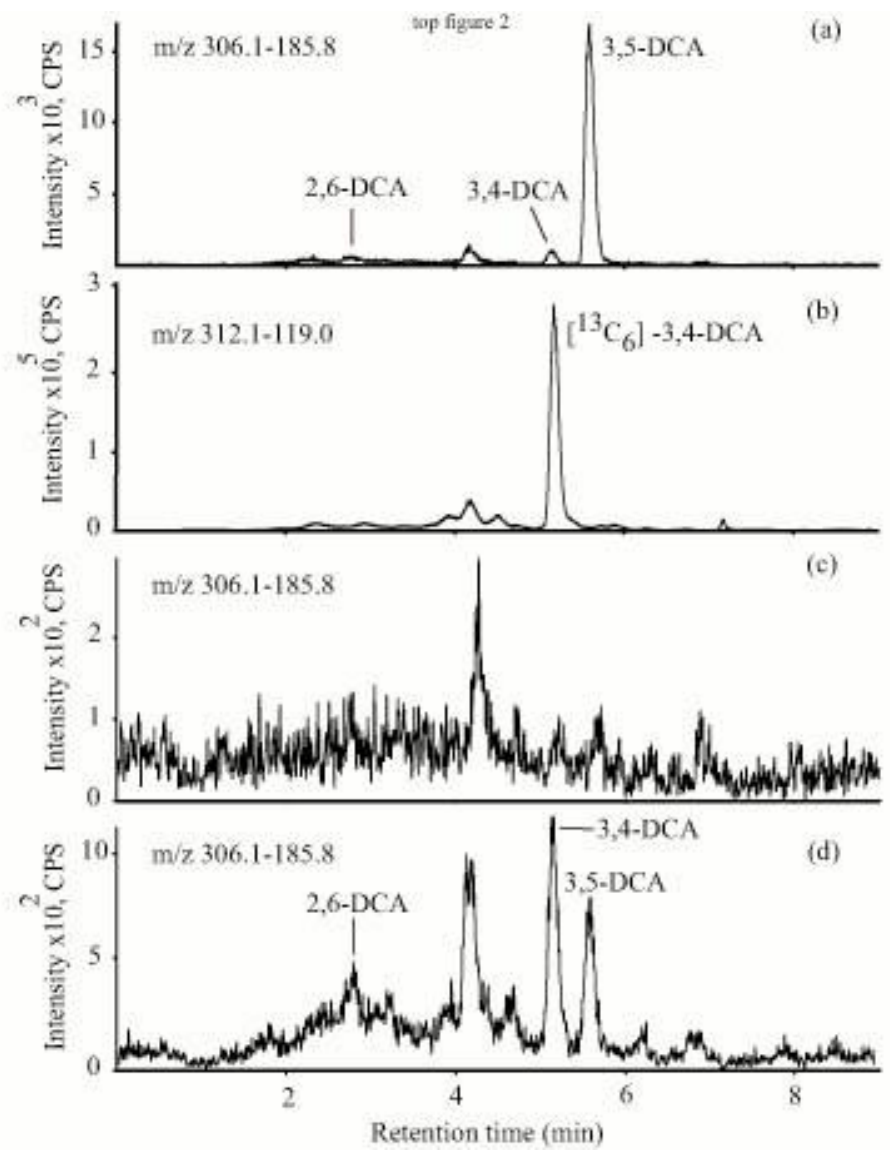

Figure 2. LC-MS/MS SRM chromatograms showing (a) a urine sample from a subject nonoccupationally exposed to DCA/pesticides. The quantified levels were for 3,5-DCA 1.2 $\mathrm{ng} / \mathrm{mL}$ and for 3,4-DCA $0.2 \mathrm{ng} / \mathrm{mL}$. (b) The trace for the internal standard $\left[{ }^{13} \mathrm{C}_{6}\right]-3,4-\mathrm{DCA}$ (c) a chemical blank showing the background noise of the instrument. (d) a urine sample from a second subject non-occupationally exposed to DCA/pesticides. The quantified levels were at the limit of detection for 3,5-DCA, $0.1 \mathrm{ng} / \mathrm{mL}$. 
The repeatability of the method was determined from spiked urine samples. At $1 \mathrm{ng} / \mathrm{mL}$, the repeatability was $10 \%(n=10)$ and at $10 \mathrm{ng} / \mathrm{mL}$ it was found to be $5 \%(\mathrm{n}=10)$. Urine samples from the experimentally exposed volunteers were hydrolysed in $5 \mathrm{M} \mathrm{NaOH}$ for $0,0.5$, $1,2,4 \mathrm{~h}$. In samples from the iprodione exposure, no free 3,5-DCA was found in the urine at time $=0$. The maximum 3,5-DCA concentration was reached after $4 \mathrm{~h}$ of hydrolysis at $100^{\circ} \mathrm{C}$. In samples from the vinclozolin exposure, about 5\% free 3,5-DCA was found. The maximum 3,5-DCA concentration was reached after $0.5 \mathrm{~h}$ of hydrolysis.

Urine samples were also spiked with vinclozolin, iprodione and 3,5-DCA and hydrolyzed at 1 and $5 \mathrm{M} \mathrm{NaOH}$. When urine was spiked with vinclozolin and iprodione, the maximum 3,5DCA concentration was seen after $2 \mathrm{~h}$ at $5 \mathrm{M} \mathrm{NaOH}$. Thereafter, a degradation was observed. This degradation was also observed when urine spiked with 3,5-DCA was hydrolyzed at 5M $\mathrm{NaOH}$. After $24 \mathrm{~h}$, less than $5 \%$ of the maximum 3,5-DCA levels were observed. Therefore, it is recommended that the samples are not hydrolyzed longer than $2 \mathrm{~h}$.

The stability of urine samples when stored at $-20^{\circ} \mathrm{C}$ was determined by reanalyzing urine samples from the experimentally exposed volunteers. Samples from the iprodione exposure were stored for 12 months whereas samples from the vinclozolin exposure were stored for 7 months between the two analyses. No degradation could be observed of either of the compounds. (Figure 3) It has been proposed that vinclozolin may not be stable in aqueous solutions. ${ }^{27}$ It has also been shown that vinclozolin may be degraded to the metabolites 2 [[(3,5-dichlorophenyl)-carbamoyl]oxy]-2-methyl-3-butenoic acid, and 3,5-dichloro-2hydroxy-2-methylbut-3-enanilide at physiological conditions in rat plasma. ${ }^{12}$ It is possible that both iprodione and vinclozolin and their metabolites are degraded in urine during storage. However, the possible degradation products seem to be converted to 3,5-DCA after hydrolysis. It is therefore possible that the choice of 3,5-DCA as a biomarker could circumvent a stability problem of these fungicides and their metabolites. 


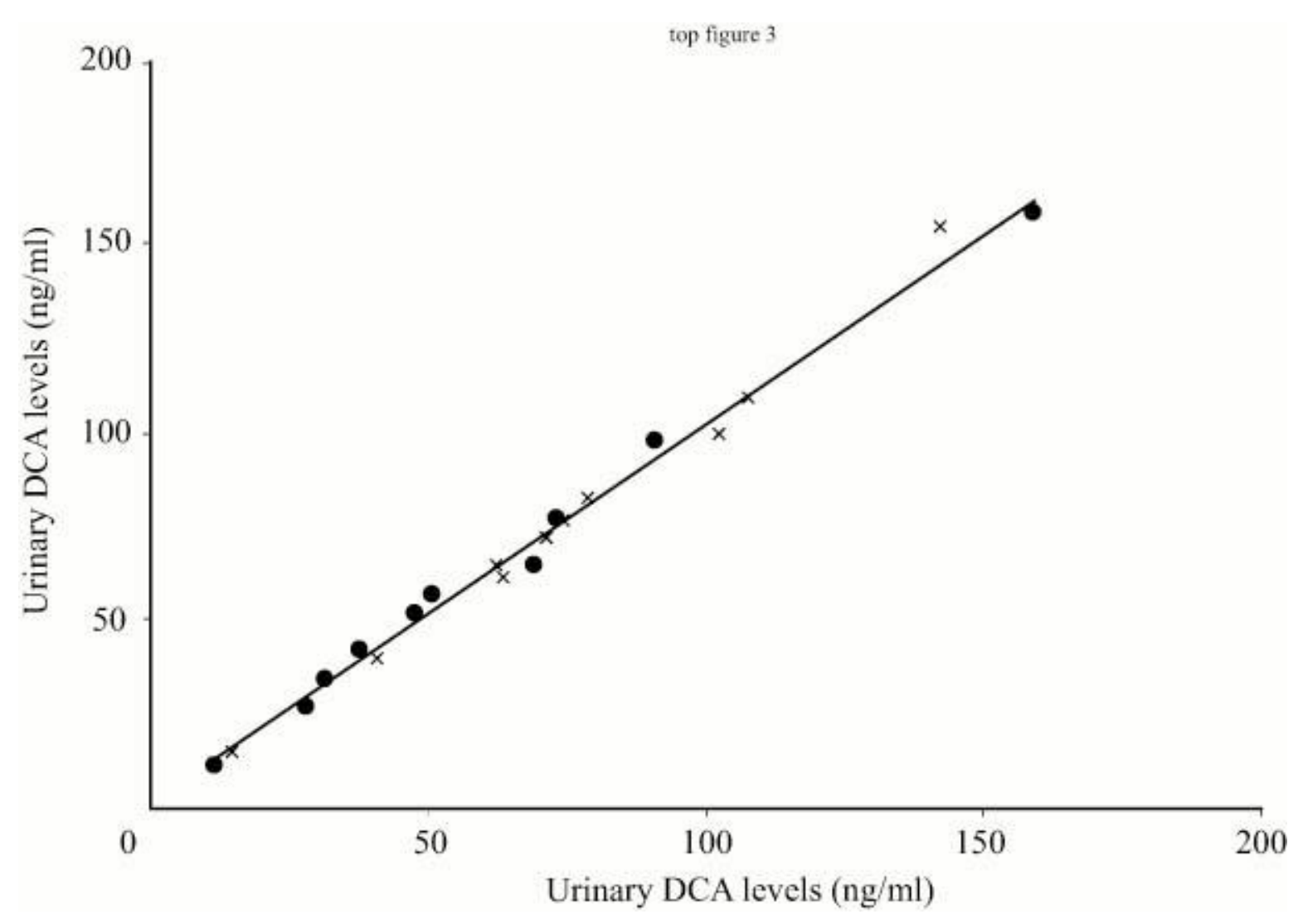

Figure 3. The stability of the urine samples after a long-term storage at $-20^{\circ} \mathrm{C}$ was determined by reanalyzing urine samples from the experimentally exposed volunteers $(n=20)$. Samples from the iprodione exposure were stored for 12 months (closed circle). Samples from the vinclozolin exposure were stored for 7 months $(\mathrm{x})$. The line represent $\mathrm{y}=\mathrm{x}$.

\section{Human experimental exposure}

\section{Iprodione}

In urine sampled before the experimental exposure, the urinary 3,5-DCA concentrations were $0.4 \mathrm{ng} / \mathrm{mL}$ for the male subject and $5 \mathrm{ng} / \mathrm{mL}$ for the female. This indicates a low level environmental exposure. After the oral ingestion of $200 \mu \mathrm{g}$ iprodione in $200 \mathrm{~mL}$ orange juice, the urinary levels rapidly increased. The maximum 3,5-DCA concentrations were reached after $5 \mathrm{~h}$ and were $99 \mathrm{ng} / \mathrm{mL}$ for the female volunteer and $168 \mathrm{ng} / \mathrm{mL}$ for the male volunteer. The half-life of elimination in urine was estimated from the slope of the curve in the loglinear concentration versus time plot. The results are shown in Table 1. It is suggested that 
3,5-DCA is excreted in urine following first order kinetics and a two compartment model. The recoveries of 3,5 -DCA in urine during the first $24 \mathrm{~h}$ were $70 \%$ and $63 \%$ for the female and male volunteer respectively. After $120 \mathrm{~h}$ the total recovery was $92 \%$ and $78 \%$.

\section{Vinclozolin}

The urinary concentrations of 3,5-DCA before exposure was $1 \mathrm{ng} / \mathrm{mL}$ for the male subject and $0.2 \mathrm{ng} / \mathrm{mL}$ for the female. After the oral ingestion of $200 \mu \mathrm{g}$ vinclozolin in $200 \mathrm{~mL}$ orange juice, the urinary levels rapidly increased. The maximum 3,5-DCA concentrations were reached after $4 \mathrm{~h}$, and were $178 \mathrm{ng} / \mathrm{mL}$ for the female volunteer and $156 \mathrm{ng} / \mathrm{mL}$ for the male volunteer. The urinary elimination of 3,5-DCA for the male subject is shown in Figure 4. The estimated half-life of elimination in urine is shown in Table 2. It is suggested that 3,5-DCA is excreted in urine following a first order kinetics and a two compartment model. The plot for the male subject is shown in figure 5. The recoveries after $24 \mathrm{~h}$ were 82 and $99 \%$ for the female and male volunteer, respectively. After $72 \mathrm{~h}$, the total recovery was 98 and $107 \%$.

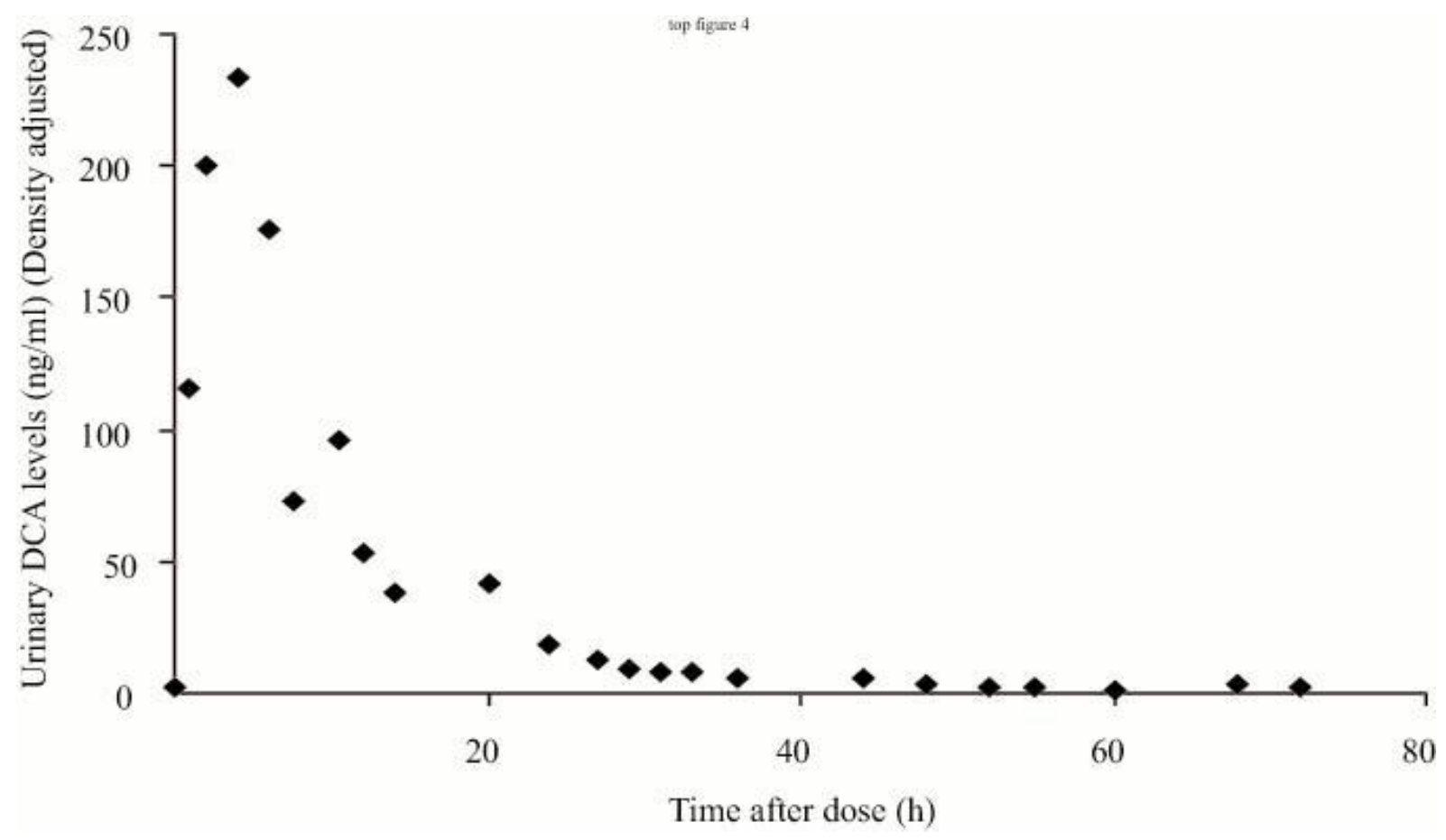

Figure 4. Urinary elimination of 3,5-DCA of the male volunteer after dosing of $200 \mu \mathrm{g}$ of vinclozolin. The urinary levels were adjusted for the urinary density. 


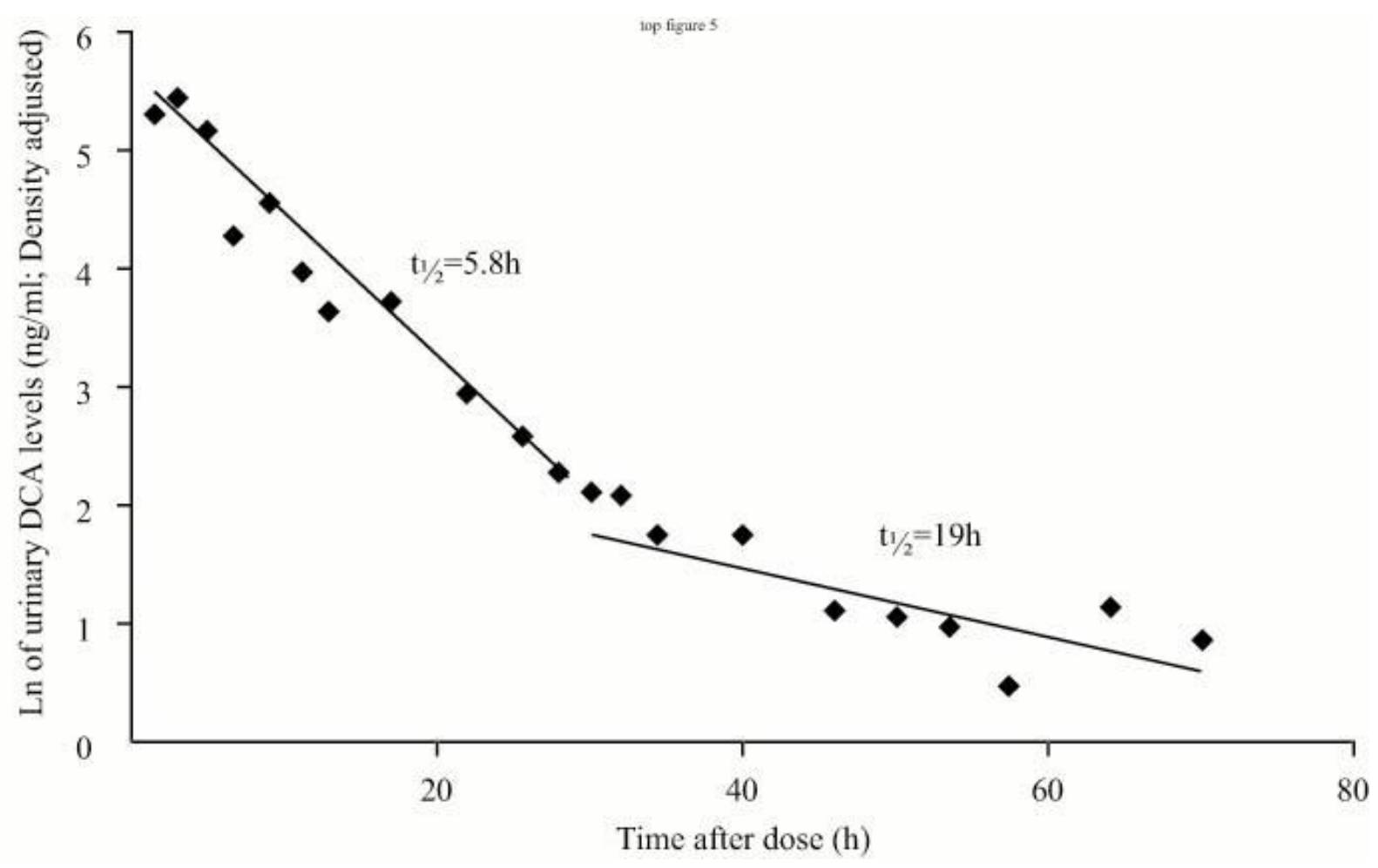

Figure 5. Urinary elimination of 3,5-DCA of the male volunteer after dosing of $200 \mu \mathrm{g}$ of vinclozolin. The half-life of elimination in urine is estimated from the slope of the curves in the log-linear concentration versus time plot. The mid point time in the intervals $2 \mathrm{~h}-27 \mathrm{~h}$ and $29 \mathrm{~h}-72 \mathrm{~h}$ were plotted against the logarithm of the density adjusted urinary levels. The elimination data suggest a two-compartment model.

\section{General discussion}

This study is limited to two individuals. Therefore it is difficult to draw conclusions about interindividual differences in the toxicokinetics of vinclozolin and iprodione. However, to our knowledge no similar studies have been published before, and the presented study may give some important indications of human metabolism and basic elimination kinetics. In this study one male and one female subject were included and they showed a similar excretion pattern of the fungicides. 
There has been a discussion for a long time on the topic of urinary dilution but no clear solution has been presented. A common method has been to use creatinine. However, creatinine levels in urine may be affected by several factors such as gender, age, muscularity, consumption of meat. In a study including both genders, it was found that the female participants had 34\% lower creatinine levels. ${ }^{28}$ A similar result was also observed in this study; the mean creatinine level for the female subject was $29 \%$ lower than the male. The male also produced a $36 \%$ larger total urinary volume than the female subject. This study indicates that an adjustment for the urinary dilution is recommended but both creatinine levels and urinary density may be applicable. However, since both male and female subjects often are and should be included in exposure assessment studies, a suggestion would be to use density for urinary dilution adjustments when applicable.

An important aspect in the validation of a biomarker is the specificity to the source of exposure. Although not investigated in this study, 3,5-DCA has also been suggested to be a biomarker of exposure to procymidione and chlozolinate. ${ }^{15}$ The presented method cannot distinguish between an exposure to the different fungicides. However, 3,5-DCA can be considered to be a very useful index of exposure for fungicides in the dicarboximide group.

There are several DCA isomers that are widely used and are important intermediates in the manufacture of dyes, pharmaceuticals and other pesticides. It has been suggested that 3,4DCA is a biomarker for the herbicides diuron, linuron, neburon, and propanil. ${ }^{15}$ In this study it was also observed that high levels of 2,6-DCA could be found after administration of the antiinflammatory diclofenac. (data not shown). In the production of azo dyes, DCA are used, however, to our knowledge the 3,5-DCA isomer does not seem to be commonly used. Figure 1 clearly shows that the isomers 3,5-DCA, 3,4-DCA and 2,6-DCA are easily separated on the analytical column and should not interfere between each other. 
The ethics of the use of controlled human experimental exposure can be discussed. However, with the rapid development of advanced LC-MS/MS techniques, experimental exposure studies to pesticides on volunteers can be conducted with exposure doses far below the recommended ADI. The exposure levels in this study are in the same magnitude as the general population can be exposed to from food. According to the Swedish national food administration, iprodione and vinclozolin remnants are among the ten most often detected pesticide residues in food. Considering this, the ethical issues should be minor.

\section{CONCLUSIONS}

A method using LC-MS/MS for the analysis of 3,5-DCA in hydrolyzed human urine has been developed. The method has a good precision and the samples are stable for up to one year of storage. In a human experimental exposure study to vinclozolin and iprodione it was shown that 3,5-DCA levels in urine rose after exposure. Between 78 and $107 \%$ of the dose was recovered as 3,5-DCA. It is suggested that the elimination in urine may follow first order kinetics and a two compartment model. The elimination half-lives was estimated to be in the range 5-7 h and 19-27 h, respectively. Although this study is limited to two individuals it gives an important indication of the human elimination of vinclozolin and iprodione. This information is valuable in the assessment of exposures and in the interpretation of biomarker levels.

\section{Acknowlegements}

This work was supported by the Swedish Environmental Protection Agency; Swedish

Research Council for Environment, Agricultural Sciences, and Spatial Planning; The Swedish Agency for International Development Cooperation; The Department for Research 
Cooperation; the Swedish Research Council and the Medical Faculty at Lund University, Sweden.

\section{REFERENCES}

1. Gray LE Jr, Ostby JS, Kelce WR. Toxicol Appl Pharmacol. 1994; 129(1): 46.

DOI:10.1006/taap.1994.1227

2. Gray LE Jr, Ostby J, Monosson E, Kelce WR. Toxicol Ind Health. 1999; 15(1-2): 48 DOI:10.1191/074823399678846646

3. Monosson E, Kelce WR, Lambright C, Ostby J, and Gary LE. Toxicol Ind Health. 1999; 15(1-2): 94. DOI:10.1191/074823399678846664

4. Gray LE, Ostby J, Furr J, Wolf CJ, Lambright C, Parks L, Veeramachaneni DN, Wilson V, Price M, Hotchkiss A, Orlando E, Guillette L. Hum Reprod Update. 2001; 7(3): 248.

DOI:10.1093/humupd/7.3.248

5. Anway MD, Memon MA, Uzumcu M, Skinner MK. J Androl. 2006 Jul 12; [Epub ahead of print]

6. Kavlock R, Cummings A. Crit Rev Toxicol. 2005; 35(8-9): 721.

DOI:10.1080/10408440591007377 
7. Zober A, Hoffmann G, Ott MG, Will W, Germann C, van Ravenzwaay B. Occup Environ Med. 1995; 52(4): 233.

8. Gray LE Jr, Wolf C, Lambright C, Mann P, Price M, Cooper RL, Ostby J. Toxicol Ind Health. 1999; 15(1-2): 94. DOI:10.1191/074823399678846664

9. Lo HH, Brown PI, Rankin GO. Toxicology 1990; 63: 215. DOI:10.1016/0300483X(90)90044-H

10.Will W. Anal Bioanal Chem. 1995; 353(2): 215. DOI:10.1007/s0021653530215

11. Carlucci G, Pasquale DD, Ruggieri F, Mazzeo P. J Chromatogr B 2005; 828 (1-2): 108. DOI:10.1016/j.jchromb.2005.08.025

12. Sierra-Santoyo A, HA Barton, MF Hughes, J. Chromatogr. B 2004; 809: 105. DOI:10.1016/j.jchromb.2004.06.002

13. Dhananjeyan MR, Erhardt PW, Corbitt C. J Chromatogr A. 2006; 1115(1-2): 8. DOI:10.1016/j.chroma.2006.02.062

14. Frias MM, Frenich AG, Martınez Vidal JL, Sanchez MM, Olea F, Olea N. J. Chromatogr. B 2001; 760 1. DOI:10.1016/S0378-4347(01)00212-2 
15. Wittke K, Hajimiragha H, Dunemann L, Begerow J. J Chromatogr B Biomed Sci Appl. 2001; 755(1-2): 215. DOI:10.1016/S0378-4347(01)00078-0

16. Weiss T, and Angerer J. J Chromatogr. B 2002; 778(1-2): 179. DOI:10.1016/S03784347(01)00542-4

17. El ML, Arellano C, Philibert C, Evrard P, Poey J, Houin G. Int J Clin Pharmacol Ther. 2002; 40(1): 41

18. Frias MM, Torres M.J., Frenich AG, Martınez Vidal JL, Olea-Serrano F, Olea N, Biomed. Chromatogr. 2004; 18: 102. DOI:10.1002/bmc.300

19. Turci R, Barisano A, Balducci C, Colosio C, Minoia C. Rapid Commun Mass Spectrom. 2006; 20(17): 262. DOI: 10.1002/rcm.2658

20. Marand Å, Karlsson D, Dalene M, Skarping G. Analyst. 2004; 129(6): 522. DOI:10.1039/b403439b

21. Wilkes MF, Woollen BH, Marsh JR, Batten PL, Chester G. Int Arch Occup Environ Health. 1993; 65: 189.

22. Woollen BH. Ann Occup Hyg. 1993; 37(5): 525.

23. Miller JC and Miller JN, Statistics and chemometrics for Analytical Chemistry, Fifth edition, Pearson education limited, Harlow, 2005. 
24. http://ec.europa.eu/food/plant/protection/evaluation/stat_active_subs_3010_en.xls

25. Mazzachi BC, Peake MJ, Ehrhardt V. Clin Lab. 2000; 46(1-2): 53.

26. Boeniger MF, Lowry LK, Rosenberg J. Am Ind Hyg Assoc J. 1993; 54(10): 615.

27. Clark T. Chemosphere 1983; 12(9-10): 1363. DOI:10.1016/0045-6535(83)90141-8

28. Åkesson B, Carnerup MA, Jönsson BAG. Scand J Work Environ Health. 2004; 30(4): 306. 
Table 1. Summary of the urinary elimination of 3,5-DCA for the two volunteers after a single oral dose of $200 \mu \mathrm{g}$ of iprodione. The half-life of elimination $\left(t_{1 / 2}\right)$ in urine is estimated from the slope of the curves in the log-linear concentration versus time plot. The mid point time in the intervals $2 \mathrm{~h}-27 \mathrm{~h}$ and $29 \mathrm{~h}-72 \mathrm{~h}$ were plotted against the logarithm of the unadjusted, density adjusted and creatinine adjusted urinary levels. The elimination data suggest a twocompartment model. The correlation coefficient (r) is given for the correlation line.

\begin{tabular}{|c|c|c|c|c|c|c|c|}
\hline Subject & $\begin{array}{l}\text { Time } \\
\text { Interval }\end{array}$ & $\begin{array}{l}t_{1 / 2} \\
\text { density } \\
\text { adjusted } \\
(\mathrm{ng} / \mathrm{ml})\end{array}$ & $r$ & $\begin{array}{l}\mathrm{t}_{1 / 2} \\
\text { creatinine } \\
\text { adjusted } \\
(\mathrm{nmol} / \mathrm{mmol})\end{array}$ & $r$ & $\begin{array}{l}\mathrm{t}_{1 / 2} \\
\text { unadjusted } \\
(\mathrm{ng} / \mathrm{ml})\end{array}$ & $r$ \\
\hline Female & $5-28 h$ & 5.7 & 0.94 & 6.7 & 0.95 & 7.5 & 0.88 \\
\hline Female & $30-72 \mathrm{~h}$ & 19.6 & 0.86 & 24.1 & 0.92 & 21 & 0.69 \\
\hline Male & $4-26 \mathrm{~h}$ & 5.3 & 0.98 & 6.7 & 0.96 & 6.7 & 0.91 \\
\hline Male & $28-72 \mathrm{~h}$ & 23.2 & 0.91 & 19.9 & 0.95 & 20 & 0.73 \\
\hline
\end{tabular}


Table 2. Summary of the urinary elimination of 3,5-DCA for the two volunteers after a single oral dose of $200 \mu \mathrm{g}$ of vinclozolin. The half-life of elimination $\left(\mathrm{t}_{1 / 2}\right)$ in urine is estimated from the slope of the curves in the log-linear concentration versus time plot. The mid point time in the intervals $2 \mathrm{~h}-27 \mathrm{~h}$ and $29 \mathrm{~h}-72 \mathrm{~h}$ were plotted against the logarithm of the unadjusted, density adjusted and creatinine adjusted urinary levels. The elimination data suggest a twocompartment model. The correlation coefficient (r) is given for the correlation line.

\begin{tabular}{|c|c|c|c|c|c|c|c|}
\hline Subject & Period & $\begin{array}{l}\mathrm{t}_{1 / 2} \\
\text { density } \\
\text { adjusted } \\
(\mathrm{ng} / \mathrm{ml})\end{array}$ & $r$ & $\begin{array}{l}\mathrm{t}_{1 / 2} \\
\text { creatinine } \\
\text { adjusted } \\
(\mathrm{nmol} / \mathrm{mmol})\end{array}$ & $r$ & $\begin{array}{l}\mathrm{t}_{1 / 2} \\
\text { unadjusted } \\
(\mathrm{ng} / \mathrm{ml})\end{array}$ & $r$ \\
\hline Female & $3-28 \mathrm{~h}$ & 6.1 & 0.98 & 7.1 & 0.99 & 7.0 & 0.80 \\
\hline Female & $28-72 \mathrm{~h}$ & 20.1 & 0.89 & 18.4 & 0.98 & 20 & 0.73 \\
\hline Male & $3-28 h$ & 5.8 & 0.96 & 5.3 & 0.99 & 6.7 & 0.64 \\
\hline Male & $28-72 \mathrm{~h}$ & 18.9 & 0.88 & 15.4 & 0.95 & 27 & 0.70 \\
\hline
\end{tabular}

